\title{
Dietary Therapies for Epilepsy
}

\author{
Eric H. Kossoff ${ }^{1}$, Huei-Shyong Wang ${ }^{2}$
}

\begin{abstract}
Since their introduction in 1921, high-fat, low-carbohydrate "ketogenic" diets have been used worldwide for refractory childhood epilepsy. Approximately half of the children have at least half their seizures reduced, including $15 \%$ who are seizure free. The mechanisms of action of dietary therapies are under active investigation and appear to involve mitochondria. Once perceived as a last resort, modifications to initiation and maintenance, as well as the widespread use of pre-made ketogenic formulas have allowed dietary treatment to be used earlier in the course of epilepsy. For infantile spasms (West syndrome) specifically, the ketogenic diet is successful about $50 \%$ of the time as a first-line treatment. New "alternative" diets such as the modified Atkins diet were created in 2003 and can be started more easily and are less restrictive. They may have particular value for countries in Asia. Side effects include constipation, dyslipidemia, growth slowing, acidosis, and kidney stones. Additionally, neurologists are studying ketogenic diets for conditions other than epilepsy, including Alzheimer's disease, autism, and brain tumors. (Biomed J 2013;36:2-8)
\end{abstract}

\section{Key words: ketogenic, diet, Atkins, epilepsy, ketosis, children}

$\mathrm{A}$ lthough many children have their seizures readily respond to anticonvulsant medications, unfortunately that is not always the case. Most child epileptologists will then consider epilepsy surgery as the next best step, but a large subset of children are either not candidates for surgery (e.g. generalized epilepsy syndromes, multifocal, or despite advances in EEG and neuroimaging an unclear focus) or the focus is in eloquent (e.g. motor, language, or memory) cortex. In our experience as well, many parents of especially very young children are not ready for epilepsy surgery until all potentially helpful options have been attempted first.

In these situations, what choices does a patient or parent have? It is not unusual to see some families counseled by their neurologist that there are no viable options available and their child will continue to have frequent disabling seizures. Today nothing could be further from the truth. There are many "nonpharmacologic" therapies available for those with intractable seizures, especially children. This does not include "alternative" therapies such as herbs, vitamins, biofeedback, and acupuncture. In fact, most epileptologists and government funding sources do not consider these therapies "alternative" any longer, but rather established, medically proven, treatments. The two major nonpharmacologic treatments for patients with epilepsy are neurostimulation devices (e.g. vagus nerve stimulators) and dietary treatments. In this review, we will cover the latter treatments, namely, using diets.

\section{History of dietary treatments}

Using diets for the treatment of epilepsy is not a new idea; in fact, it is one of the oldest treatments for epilepsy in existence. In the 1920s and 1930s, there were no anticonvulsants other than phenobarbital and bromides available for the treatment of epilepsy in children or even adults. As a result, the ketogenic diet (KD) was created in 1921 at the Mayo Clinic in Rochester, Minnesota, USA, by Dr. Wilder for children with refractory epilepsy. ${ }^{[1]}$ This new treatment restricted carbohydrates, protein, calories, and fluids while significantly increasing fat intake to comprise at least $90 \%$ of calories. This treatment was designed to mimic the effects of starvation, which had been recognized for centuries as therapeutic for epilepsy.

Although initially very popular, as new anticonvulsants such as phenytoin became introduced, the popularity of the

From the ${ }^{1}$ Departments of Neurology and Pediatrics, The Johns Hopkins University, U.S.A., ${ }^{2}$ Division of Pediatric Neurology, Department of Pediatrics, Chang Gung Children's Hospital at Linkou, Chang Gung University College of Medicine, Taoyuan, Taiwan (R.O.C).

Received: Sep. 23, 2011; Accepted: May 11, 2012

Correspondence to: Dr. Eric H. Kossoff, Departments of Neurology and Pediatrics, The Johns Hopkins University, U.S.A. Suite 2158 - 200 North Wolfe Street, Baltimore, Maryland 21287, U.S.A. Tel: 1-410-9554259; Fax: 1-410-6142297; E-mail: ekossoff@ jhmi.edu

DOI: $10.4103 / 2319-4170.107152$ 
KD waned, with usage primarily limited to select academic institutions and as a last resort for children with severe epilepsy. After the creation of the Charlie Foundation parent support group in 1994 by the father of a child with seizures treated at Johns Hopkins Hospital in Baltimore, Maryland, interest was reawakened in the United States and then around the world 3-4 years later. ${ }^{[2]}$

It is an exciting time for those who use the KD, now nearly 20 years since the founding of the Charlie Foundation. Nearly 100 new articles devoted to dietary therapy per year are being published. Large international symposia devoted to the use of dietary therapies have been held in Phoenix, Arizona, USA in 2008, Edinburgh, UK in 2010, and a third is planned for Chicago, Illinois, USA in September 2012. The years 2008 and 2009 were the most dramatic for KD research with two prospective controlled trials demonstrating efficacy of the KD and an International Consensus Statement guiding ideal use and management for neurologists and dietitians. ${ }^{[3-5]}$ There are now four different KDs available to choose from: the traditional "classic" KD, the medium-chain triglyceride (MCT) diet, the modified Atkins diet (MAD), and the low glycemic index treatment (LGIT). Diets are being used for adults, as new-onset therapy, and in conditions other than epilepsy. All of these startling developments will be discussed in this review.

\section{What is the KD?}

The KD is a high-fat, adequate protein, low-carbohydrate diet that was originally designed to mimic the effects of fasting, but for extended periods [Table 1]. Calories are often restricted to $85-90 \%$ of the estimated daily requirements, and fluids are also slightly reduced ${ }^{[5]}$ The evidence for both fluid and calorie restriction is scant, however, and many centers (including ours) no longer do this. The diet "prescription" includes a ratio of fat to carbohydrate and protein combined, with 4:1 being the most common starting ratio. ${ }^{[6]}$ Lower ratios, most typically 3:1 or 2:1, are utilized for infants, adolescents, and/or patients in whom higher protein and carbohydrate contents are desired due to either tolerability or side effects. ${ }^{[5]}$ Children are all universally given a multivitamin, mineral, and calcium supplement. Now 90 years later, the KD is generally unchanged in its composition. Foods given often include butter, cream, oils, mayonnaise, fish, chicken, and steak. The KD can also be given to infants or children with gastrostomy tubes easily as a formula preparation, including a $4: 1$ or $3: 1$ premixed powder or liquid (Nutricia KetoCal $\left.{ }^{\mathrm{TM}}\right){ }^{\left[{ }^{[7]}\right.}$ Other formulas have also been created in the United States (KetoVolve ${ }^{\mathrm{TM}}$ ), Korea $\left(\right.$ Ketonia $\left.^{\mathrm{TM}}\right)$, and Japan (Ketonoformula ${ }^{\mathrm{TM}}$ ).

Many investigators have attempted to change the methods of providing and starting the KD in order to improve tolerability, therefore making dietary therapy a more attrac-
Table 1: Comparison of the four major ketogenic diets in clinical use (1000 kcal/day provided)

\begin{tabular}{lccc}
\hline Diet & $\begin{array}{c}\text { Fat }(\mathbf{g}), \% \\
\text { calories }\end{array}$ & $\begin{array}{c}\text { Protein }(\mathbf{g}), \% \\
\text { calories }\end{array}$ & $\begin{array}{c}\text { Carbohydrate } \\
(\mathbf{g}), \% \text { calories }\end{array}$ \\
\hline $\begin{array}{l}\text { Classic long chain } \\
\text { triglyceride }\end{array}$ & $100(90 \%)$ & $17(7 \%)$ & $8(3 \%)$ \\
$4: 1$ & 96 & 18 & 14 \\
$3: 1$ & 92 & 20 & 26 \\
$2: 1$ & 77 & 37 & 40 \\
$1: 1$ & $78(70 \%)$ & $25(10 \%)$ & $50(20 \%)$ \\
Medium chain & & & $40-60(27 \%)$ \\
triglyceride oil diet & $67 *(45 \%)$ & $40-60 *$ & $10-20(5 \%)$ \\
Low glycemic index & & $(28 \%)$ & \\
treatment & $70 *(70 \%)$ & $60 *(25 \%)$ & \\
Modified Atkins diet & 70 & & \\
*Values are approximate & & &
\end{tabular}

tive option for families nervous about how tough it can be. The KD is traditionally implemented in the hospital by a trained dietitian with calories advanced slowly after a 24-48 $\mathrm{h}$ fasting period. During this fasting period, blood glucose is checked approximately every $4-6 \mathrm{~h}$ and urine ketones daily. Parents are educated regarding how to weigh and measure foods during the admission period. Over a 3-day period, the calories are gradually increased until maximal and then the child is discharged home with parents.

Many of these traditional aspects of KD initiation have been challenged in recent years, however. Evidence from a randomized trial performed in Philadelphia, USA suggests that the fast may not be necessary, although the seizure control may occur quicker when children are fasted. ${ }^{[8,9]}$ As a result of this important study, other investigators have continued to look at alternative ways to start as well as maintain the KD. Research has shown that the KD can be started as an outpatient and with lower ratios, and maintained without the same level of restrictiveness on calories, fluids, and protein. ${ }^{[5,10]}$ Most centers today in United Kingdom no longer admit children to the hospital to start the diet in fact. Some centers will start the KD at full calories and gradually increase the ketogenic ratio (rather than calories) over a 3-day period.

Once started, a trained pediatric dietitian often adjusts the KD at periodic, often every 3-month, follow-up clinic visits in order to optimize growth, nutrition, and efficacy. ${ }^{[5]}$ Laboratory studies including complete blood count, comprehensive metabolic profile, and fasting lipid panel should be obtained prior to each clinic visit. An international group of physicians and dietitians, experts in the $\mathrm{KD}$, published a consensus statement regarding ideal implementation and management in 2009 in order to help guide what tests should be performed in children and how best to administer the diet. ${ }^{[5]}$ However, this consensus statement has remarkable flexibility inherent in the protocols, recognizing the myriad ways in which some international centers have adapted the 
diet for their country and culture. The diet can be successfully used for many religions, food allergies, and even for vegetarian families.

The KD is typically continued for 3-6 months if not successful and 2 years if it is.$^{[5]}$ However, if efficacious and seizures are still persisting (although reduced), many families will wish to continue the KD for much longer, occasionally decades in some situations. ${ }^{[1]}$ Similar to anticonvulsant medications, if a neurologist wishes to discontinue the diet, it should be done gradually. A recent article by Worden et al, found that the KD can be successfully discontinued over several weeks, as opposed to the traditional 6 months, without worsening of seizures in most situations. ${ }^{[12]}$ This allows families to move on more rapidly to both regular foods and perhaps new anticonvulsants when it is time to end the KD.

\section{Proof of efficacy}

Hundreds of studies over the past two decades have shown remarkably similar results. Approximately 50-60\% of children will have at least a $>50 \%$ seizure reduction, with one third have $>90 \%$ response. ${ }^{[13-15]}$ Over 1 in 10 will become seizure free. This is remarkable considering how often intractable their epilepsy may be, and how overall unlikely anticonvulsants would be to improve their seizures. Efficacy with the KD does not appear to decrease over the years, and children can have seizure control many years later, surprisingly even after the KD has been stopped in some circumstances. ${ }^{[16,17]}$

The KD appears to work equally well for any age or gender ${ }^{[5]}$ However, there are some epilepsy syndromes and situations in which the KD may show better (or worse) efficacy [Table 2]. ${ }^{[5]}$ Not long ago, a KD review article would not mention any epilepsy indications for the KD other than glucose transporter-1 (GLUT-1) deficiency or pyruvate dehydrogenase (PDH) deficiency. Children with LennoxGastaut syndrome were the most commonly started on the $\mathrm{KD}$, despite no specific published evidence of benefit for that condition.

This situation has changed recently, as evident in Table 1 of the 2009 consensus statement, which lists indications for the KD. ${ }^{[5]}$ These include myoclonic-astatic epilepsy, tuberous sclerosis complex, Rett syndrome, infantile spasms, Dravet syndrome, and children receiving only formula. Mitochondrial disorders also appear to do very well with KD therapy. ${ }^{[18]}$ The data justifying the use of the KD for Dravet syndrome and myoclonic-astatic epilepsy have grown even more since the 2009 consensus statement was published. ${ }^{[19,20]}$

Of all these indications, however, perhaps the fastest growing and most established is infantile spasms (West syndrome). Research by Hong and colleagues in 104 consecutive infants demonstrated that $64 \%$ would have $>50 \%$ spasm reduction using an intent-to-treat analysis. ${ }^{[21]}$
Table 2: Potential indications and contraindications for dietary therapy

Probable benefit (at least two publications)

Glucose transporter protein-1 (GLUT-1) deficiency

Pyruvate dehydrogenase deficiency (PDHD)

Myoclonic-astatic epilepsy (Doose syndrome)

Tuberous sclerosis complex

Rett syndrome

Severe myoclonic epilepsy of infancy (Dravet syndrome)

Infantile spasms

Selected mitochondrial disorders

Children receiving only formula (infants or enterally fed patients)

Suggestion of benefit (one case report or series)

Landau-Kleffner syndrome

Lafora body disease

Combined use with vagus nerve stimulation

Combined use with zonisamide

Children with recently worsened seizures in the past month

Contraindications (*relative)

Pyruvate carboxylase deficiency

Porphyria

Beta-oxidation defects

Primary carnitine deficiency

Inadequate ability to maintain nutrition or comply with the KD

restrictions

Combined use with phenobarbital*

Children with a clear focal lesion potentially resectable*

Severe gastroesophageal reflux*

Perhaps most remarkably, $37 \%$ had at least 6 months of spasm freedom during treatment. Kang et al, randomized 40 spasmfree infants treated with the KD to either stop the diet after 8 months or after the more traditional 24 months. ${ }^{[22]}$ The risk of spasm recurrence was equal between groups, and growth disturbance was higher in the children treated longer, suggesting short KD periods are justified in infantile spasms. ${ }^{[22]}$ The $\mathrm{KD}$ also appears to be helpful for infantile spasms as a firstline therapy, which will be discussed later in this review. ${ }^{[23]}$

There have been several new epilepsy conditions with published evidence suggesting the strong benefit of the $\mathrm{KD}$, most notably refractory status epilepticus. The epilepsy condition entitled FIRES (fever-induced refractory epilepsy syndrome), often difficult to control with poor developmental outcomes, appears to be very susceptible to the KD. ${ }^{[24]}$ For patients in status epilepticus, the KD is a very feasible option and requires primarily switching the patient's nasogastric tube formula from standard to ketogenic, with successful results typically described within 7-10 days [Table 3]. ${ }^{[25]}$ Other new conditions reported recently include childhood absence epilepsy and SturgeWeber syndrome. ${ }^{[26,27]}$

\section{Mechanisms of action}

Despite nearly 100 years of use, the mechanism (or 
Table 3: Published reports of the ketogenic diet for status epilepticus

\begin{tabular}{lccc}
\hline Author (year) & Subjects & Age (years) & Time to response \\
\hline Bodenant (2008) & 1 & 54 & 7 days \\
Villeneuve (2009) & 5 & $1-10$ & $1-10$ days \\
Kumada (2009) & 2 & 5 & 5,10 days \\
Wusthoff (2010) & 2 & 29,34 & 4,8 days \\
Nabbout (2010) & 9 & $5-8$ & $4-6$ days \\
Cervenka (2011) & 1 & 49 & 7 days \\
Ismail (2011) & 1 & 14 & 10 days \\
Nam (2011) & 5 & $4-40$ & $1-19$ days \\
\hline
\end{tabular}

mechanisms) of action of the KD remains somewhat unclear. ${ }^{[28]}$ Although previously believed to involve ketosis (hence the term "ketogenic" diet), many researchers believe ketosis is not the primary way these diets work but rather represents a marker of the metabolic shift that occurs with this treatment. ${ }^{[28]}$ Evidence from the MAD and LGIT also lend credence to this theory as both treatments have lower and less stable ketone levels, yet similar efficacy to the KD. The glycolysis inhibitor 2-deoxy-D-glucose (2DG), which has been proposed as a possible pharmacologic mimic of the $\mathrm{KD}$, appears to have a different acute seizure test profile than the $\mathrm{KD}$, indicating that lowering the serum glucose levels may not be the primary reason why the KD is effective. ${ }^{[29]}$ A lack of effect of serum glucose on efficacy has also been noted in clinical studies as well. ${ }^{[30]}$

Current research in animals involves calorie restriction, increased levels of CSF amino acids and neurotransmitters, potassium ATP channel activation, effects on adenosine, glucose stabilization, glycolysis inhibition, direct effects of polyunsaturated fatty acids (PUFAs), and still potential effects of individual ketone bodies ( $\beta$-hydroxybutyrate, acetone, and acetoacetate). ${ }^{[28,31,32]}$ The KD appears to improve energy metabolism of neurons, probably through mitochondria and mitochondrial uncoupling proteins. ${ }^{[33]}$ There may be different mechanisms at work for the effect of the KD on different epilepsy syndromes, and very few of these theories fully explain the often immediate reduction in seizures noted during the initial hours of fasting, even before any actual food is given. ${ }^{[34]}$

\section{New "alternative" diets}

Despite the much less restrictive way in which the diet is started and maintained nowadays, there are still many parents of children with epilepsy who are concerned about the difficulty in changing their lifestyle to adopt a KD. This may be especially true in Asia with sharing of foods and rice in the diet. Some of these patients include busy families with multiple children, adolescents, adults, and patients who do not eat fat. For these children, the new "alternative" diets may be options that can allow dietary treatment to be tried.
The first alternative diet, the MCT diet, has been used since the 1970s, and this diet utilizes more of the extremely ketogenic oil in order to allow for more carbohydrates. ${ }^{[35]}$ It is generally equivalent to the classic KD and is used mostly in United Kingdom and Canada today. The LGIT was first published by Dr. Elizabeth Thiele and Heidi Pfeifer from Massachusetts General Hospital in Boston, USA in 2005. ${ }^{[36]}$ This diet provides carbohydrates with glycemic indicies $<50$ (e.g. berries, whole grain, green vegetables) in order to maintain stable blood glucose levels. ${ }^{[36]}$ Although serum ketones do increase on the LGIT, they are extremely low and not measurable in urine, and the LGIT is started as an outpatient without a fast. An update in 2009 from the same group now includes 76 children, of whom $50 \%$ of those remaining on the diet at 3 months had $>50 \%$ seizure reduction. ${ }^{[37]}$

The fourth and final alternative KD, entitled the modified Atkins diet (MAD), was created and published by the author Eric Kossoff from Baltimore, USA in 2003. ${ }^{[38]}$ The MAD is also started as an outpatient without a fast, but does not restrict calories, fluid, or protein. ${ }^{[38]}$ Carbohydrates are restricted to $10 \mathrm{~g} /$ day (children) or $20 \mathrm{~g} /$ day (adults), and fats are strongly encouraged in order to maintain ketosis. ${ }^{[39,40]}$ There are now 22 combined publications to our knowledge about the use of the MAD in children and adults, with 123 (44\%) of 280 total subjects having $>50 \%$ seizure reduction after 6 months, of which 72 (26\%) had $>90 \%$ improvement. These results are quite similar to those described in the KD. One recent publication suggests that using one of the KD formulas (Nutricia KetoCal ${ }^{\mathrm{TM}}$ ) during the initial month may in fact boost the efficacy of the MAD by providing additional fat sources. ${ }^{[41]}$ Other high-fat formulas or even oils may likely be similarly beneficial. Children can be switched from the MAD to the KD, with $30 \%$ of those switched having additional seizure improvement, especially if their underlying condition was myoclonic-astatic epilepsy (Doose syndrome).$^{[2]}$ We routinely use the MAD for adolescents and adults at Johns Hopkins Hospital now instead of the KD.

\section{Side effects}

Side effects do occur with dietary therapies as these treatments are neither organic nor designed to be healthy. However, most of the adverse effects are treatable, especially hypercholesterolemia (with ratio or fat composition changes), mineral deficiencies, acidosis, constipation, and weight loss (with extra calories). ${ }^{[5,43]}$ An important change in the mindset of neurologists and dietitians at KD centers is to now prevent these side effects before they actually occur. Starting without a fast or using an alternative diet could potentially help, especially in the short term. ${ }^{[8]}$

One way to prevent side effects may be including the automatic use of supplements such as calcium, carnitine, selenium, zinc, and Vitamin D ${ }^{[5,44]}$ A study of oral citrates 
(Polycitra $\mathrm{K}^{\mathrm{TM}}$ ) as an empiric, universal supplement to children on the KD found a reduction in the incidence of kidney stones from $6.9 \%$ to $0.9 \%(p=0.02) .{ }^{[45]}$ Continued work into potentially avoiding side effects before they even occur will improve the tolerability of dietary therapies, expanding their use.

Long-term side effects with prolonged use of dietary therapies can occur with higher prevalence than short-term ones. These include kidney stones, bone fractures, and decreased linear growth. ${ }^{[46]}$ Should it prove useful and be necessary in the long term, it may be reasonable to consider changing these patients to the MAD or LGIT after several years. Recent data from Patel have also determined that in children who were on the KD years before (but have discontinued it), there are no obvious long-term effects on growth, cholesterol, or cardiac health. ${ }^{[16]}$ Further research into long-term effects is necessary.

\section{Adults}

In the earliest days of the $\mathrm{KD}$, adults were treated equally to children, with a study from Barborka in 1930 reporting excellent efficacy similar to the pediatric age group. ${ }^{[47]}$ However, the KD became perceived as too restrictive for adults in the subsequent decades, perhaps due to an erroneous belief that adults would not be compliant with a restrictive dietary therapy. With the widespread use of the MAD, this situation has changed. Research would suggest that the MAD can be helpful in also approximately half of the adults and the potential benefits of weight loss may influence some obese adults to try this treatment. ${ }^{[40]}$ Using dietary treatments may also have value for women considering pregnancy and those with medication side effects. Adult epilepsy diet centers have opened in 2010 in Baltimore and London.

\section{First-line use}

As discussed previously in this review, there are several "indications" for using the KD based on strong evidence for seizure reduction. For infantile spasms specifically, the results would suggest that younger children and those with fewer previously tried anticonvulsants are more likely to have a $>90 \%$ response. ${ }^{[21]}$ Therefore, one would have to consider the use of the KD sooner in the course of epilepsy. Over the past 5 years, especially at our institution, we have offered the KD as a formula for parents of children with infantile spasms as a first-line therapy instead of adrenocorticotropic hormone $(\mathrm{ACTH})$ or vigabatrin, typically when infants are seen quickly after spasms begin. In 2008, we reported our results in comparison to ACTH. ${ }^{[23]}$ There was no statistical difference between the diet and $\mathrm{ACTH}$, and the spasm recurrence rate was lower with the $\mathrm{KD}$, perhaps as it could be continued for 6 months (unlike ACTH which is typically stopped after $1-2$ months). ${ }^{[23]} \mathrm{A}$ family has created a foundation entitled the Carson Harris Foundation based on their personal experience to help promote the concept of using the diet first-line for infantile spasms (www.carsonharrisfoundation.org).

We suspect that this is the future of the KD, but it requires faith in the efficacy of the $\mathrm{KD}$ on the part of the neurologist and dietitian, and also willingness to give the diet for at least 2-3 weeks to work on the part of the parent (or patient). KD formulas and alternative diets such as the MAD may improve the ease of using dietary treatments first line as well. Lastly, dietitians would have to be available on an almost urgent basis in some situations for this to be feasible.

\section{Non-epilepsy uses}

In a manner similar to anticonvulsants, which are used for migraine and bipolar disorder, the KD is being examined for neurologic conditions other than just epilepsy. ${ }^{[48]}$ It seems that nearly all possible neurologic conditions have been reported in the past decade in either animal studies or limited human trials, including autism, hypoxic-ischemic encephalopathy, amyotrophic lateral sclerosis, and traumatic brain injury. ${ }^{[48]}$ The three conditions that have been studied the most are brain tumors, Alzheimer disease, and migraine. These will be discussed in more detail.

Brain tumors have been investigated in mice, with results showing benefit theorized to be primarily due to calorie restriction rather than ketosis or any other mechanism of action. ${ }^{[49]}$ A prospective trial in Germany of a low-carbohydrate diet (70 $\mathrm{g}$ of carbohydrate per day) for 16 adults with advanced metastatic cancer has been recently published. ${ }^{[50]}$ Five appeared to have some stability of their disease and improvement in quality of life, suggesting further study is warranted. ${ }^{[50]}$ Alzheimer disease was also first studied in mice with some reduction in amyloid beta proteins 40 and 42 leading to the marketing of an MCT powder supplement entitled "Axona" which is available for sale in the United States today. ${ }^{[1,52]}$ Lastly, migraine had been studied in the 1930s only, so our center decided to also investigate KD for this condition today. As anticonvulsants such as topiramate and valproate can be helpful for migraine prophylaxis, we studied eight adolescents with chronic daily headaches using the MAD ${ }^{[53]}$ Unfortunately, the trial was unsuccessful with low efficacy, poor recruitment, and the study was ended prematurely. ${ }^{[53]}$ It may be helpful perhaps for adults with less frequent or severe headaches according to a recent published commentary from Italy, but in this population it was not. ${ }^{[54]}$ Regardless, it is likely that for different neurologic conditions the KD may have differing mechanisms of action. ${ }^{[5]}$

\section{Use in Asia?}

A potentially very promising region of the world for 
which dietary therapies may be very advantageous is Asia. Large populations, occasional unavailability of certain anticonvulsants (or surgery), and a strong interest in using dietary manipulation rather than traditional medicine by patients create a hospitable climate for consideration of this therapy. Already today, the KD is well established with publications from centers in Taiwan, Korea, India, and Japan. ${ }^{[6,15,56,57]}$

One key to further advancement of the use of dietary treatments throughout Asia may involve using the MAD. ${ }^{[58]}$ Several advantages include limited need for dietitian involvement, greater flexibility for carbohydrates such as rice, increased ability to share foods at the table with family members, and improved palatability. Computer programs such as KetoCalculator (www.ketocalculator.com) are also accessible in Asia and allow for greater food recipes and variety. Based on work from rural Honduras, in which dietitian support is not available but the MAD was successfully implemented, Ms. Jeanne Riether, a parent advocate in Heilongjiang, China, is helping stimulate the use of the MAD at Harbin Children's Hospital and throughout China. ${ }^{\text {[59] Her website (www.healingyounghearts.org/wordpress) }}$ includes information about dietary therapies for China.

\section{Conclusions}

The use of KD for epilepsy continues to grow in popularity worldwide. Recent attempts to make the diet more palatable, easier to start, and safer to maintain have expanded its use. No longer are dietary treatments used only as a last resort and solely for children. Basic scientists and neurologists are becoming interested in dietary therapies as well for conditions other than epilepsy. Dietary treatment will continue to grow and expand in usage throughout Asia and Taiwan.

\section{REFERENCES}

1. Wilder RM. The effect of ketonemia on the course of epilepsy. Mayo Clin Bull 1921;2:307-8.

2. Kossoff EH, McGrogan JR. Worldwide use of the ketogenic diet. Epilepsia 2005;46:280-9.

3. Neal EG, Chaffe H, Schwartz RH, Lawson MS, Edwards N, Fitzsimmons G, et al. The ketogenic diet for the treatment of childhood epilepsy: A randomized controlled trial. Lancet Neurol 2008;7:500-6.

4. Freeman JM, Vining EP, Kossoff EH, Pyzik PL, Ye X, Goodman $\mathrm{SN}$. A blinded, crossover study of the ketogenic diet. Epilepsia 2009;50:322-5.

5. Kossoff EH, Zupec-Kania BA, Amark PE, Ballaban-Gil KR, Bergqvist AC, Blackford R, et al. Charlie Foundation, and the Practice Committee of the Child Neurology Society. Optimal clinical management of children receiving the ketogenic diet: Recommendations of the International Ketogenic Diet Study Group. Epilepsia 2009;50:304-17.

6. Seo JH, Lee YM, Lee JS, Kang HC, Kim HD. Efficacy and tolerability of the ketogenic diet according to lipid:nonlipid ratios--comparison of 3:1 with 4:1 diet. Epilepsia 2007;48:801-5.

7. Kossoff EH, McGrogan JR, Freeman JM. Benefits of an all-liquid ketogenic diet. Epilepsia 2004;45:1163.

8. Bergqvist AG, Schall JI, Gallagher PR, Cnaan A, Stallings VA. Fasting versus gradual initiation of the ketogenic diet: A prospective, randomized clinical trial of efficacy. Epilepsia 2005;46:1810-9.

9. Kossoff EH, Laux LC, Blackford R, Morrison PF, Pyzik PL, Turner Z, et al. When do seizures improve with the ketogenic diet? Epilepsia 2008;49:329-33.

10. Vaisleib II, Buchhalter JR, Zupanc ML. Ketogenic diet: Outpatient initiation, without fluid, or caloric restrictions. Pediatr Neurol 2004;31:198-202.

11. Kossoff EH, Turner Z, Bergey GK. Home-guided use of the ketogenic diet in a patient for over twenty years. Pediatr Neurol 2007;36:424-5.

12. Worden LT, Turner Z, Pyzik PL, Rubenstein JE, Kossoff EH. Is there an ideal way to discontinue the ketogenic diet? Epilepsy Res 2011;95:232-6.

13. Keene DL. A systematic review of the use of the ketogenic diet in childhood epilepsy. Pediatr Neurol 2006;35:1-5.

14. Henderson CB, Filloux FM, Alder SC, Lyon JL, Caplin DA. Efficacy of the ketogenic diet as a treatment option for epilepsy: Meta-analysis. J Child Neurol 2006;21:193-8.

15. Mak SC, Chi CS, Wan CJ. Clinical experience of ketogenic diet on children with refractory epilepsy. Acta Paediatr Taiwan 1999;40:97-100

16. Patel A, Pyzik PL, Turner Z, Rubenstein JE, Kossoff EH. Longterm outcomes of children treated with the ketogenic diet in the past. Epilepsia 2010;51:1277-82.

17. Marsh EB, Freeman JM, Kossoff EH, Vining EP, Rubenstein JE, Pyzik PL, et al. The outcome of children with intractable seizures: A 3- to 6-year follow-up of 67 children who remained on the ketogenic diet less than one year. Epilepsia 2006;47:425-30.

18. Kang HC, Lee YM, Kim HD, Lee JS, Slama A. Safe and effective use of the ketogenic diet in children with epilepsy and mitochondrial respiratory chain defects. Epilepsia 2007;48:82-8.

19. Veggiotti P, Burlina A, Coppola G, Cusmai R, De Giorgis V, Guerrini R, et al. The ketogenic diet for Dravet syndrome and other epileptic encephalopathies: An Italian consensus. Epilepsia 2011;52 Suppl 2:83-9.

20. Kilaru S, Bergqvist AG. Current treatment of myoclonic astatic epilepsy: Clinical experience at the Children's Hospital of Philadelphia. Epilepsia 2007;48:1703-7.

21. Hong AM, Hamdy RF, Turner Z, Kossoff EH. Infantile spasms treated with the ketogenic diet: Prospective single-center experience in 104 consecutive infants. Epilepsia 2010;51:1403-7.

22. Kang HC, Lee YJ, Lee JS, Lee EJ, Eom S, You SJ, et al. Comparison of short-term versus long-term ketogenic diet for intractable infantile spasms. Epilepsia 2011;52:781-7.

23. Kossoff EH, Hedderick EF, Turner Z, Freeman JM. A case-control evaluation of the ketogenic diet versus ACTH for new-onset infantile spasms. Epilepsia 2008;49:1504-9.

24. Nabbout R, Mazzuca M, Hubert P, Peudennier S, Allaire C, Flurin $\mathrm{V}$, et al. Efficacy of ketogenic diet in severe refractory status epilepticus initiating fever induced refractory epileptic encephalopathy in school age children (FIRES). Epilepsia 2010;51:2033-7.

25. Kossoff EH. The fat is in the fire: ketogenic diet for refractory status epilepticus. Epilepsy Curr 2011;11:88-9. 
26. Groomes LB, Pyzik PL, Turner Z, Dorward JL, Goode VH, Kossoff EH. Do patients with absence epilepsy respond to ketogenic diets? J Child Neurol 2011;26:1601-5.

27. Kossoff EH, Bosarge JL, Comi AM. A Pilot Study of the Modified Atkins Diet for Sturge-Weber Syndrome. Epilepsy Res 2010;92:240-3.

28. Bough KJ, Rho JM. Anticonvulsant mechanisms of the ketogenic diet. Epilepsia 2007;48:43-58.

29. Stafstrom CE, Ockuly JC, Murphree L, Valley MT, Roopra A, Sutula TP. Anticonvulsant and antiepileptic actions of 2-deoxyD-glucose in epilepsy models. Ann Neurol 2009;65:435-47.

30. Bergqvist AG, Schall JI, Richard EL, Gallagher PR, Stallings VA. Predictive power of first morning glucose and the ketogenic diet. Neuropediatrics 2007;38:193-6.

31. Garriga-Canut M, Schoenike B, Qazi R, Bergendahl K, Daley TJ, Pfender RM, et al. 2-Deoxy-D-glucose reduces epilepsy progression by NRSF-CtBP-dependent metabolic regulation of chromatin structure. Nat Neurosci 2006;9:1382-7.

32. Masino SA, Li T, Theofilas P, Sandau US, Ruskin DN, Fredholm $\mathrm{BB}$, et al. A ketogenic diet suppresses seizures in mice through adenosine A receptors. J Clin Invest 2011;121:2679-83.

33. Bough KJ, Wetherington J, Hassel B, Pare JF, Gawryluk JW, Greene JG, et al. Mitochondrial biogenesis in the anticonvulsant mechanism of the ketogenic diet. Ann Neurol 2006;60:223-35.

34. Freeman JM, Vining EP. Seizures decrease rapidly after fasting: Preliminary studies of the ketogenic diet. Arch Pediatr Adolesc Med 1999;153:946-9.

35. Schwartz RH, Eaton J, Bower BD, Aynsley-Green A. Ketogenic diets in the treatment of epilepsy: Short-term clinical effects. Dev Med Child Neurol 1989;31:145-51.

36. Pfeifer HH, Thiele EA. Low-glycemic-index treatment: A liberalized ketogenic diet for treatment of intractable epilepsy. Neurology 2005;65:1810-2.

37. Muzykewicz DA, Lyczkowski DA, Memon N, Conant KD, Pfeifer HH, Thiele EA. Efficacy, safety, and tolerability of the low glycemic index treatment in pediatric epilepsy. Epilepsia 2009;50:1118-26.

38. Kossoff EH, Krauss GL, McGrogan JR, Freeman JM. Efficacy of the Atkins Diet as therapy for intractable epilepsy. Neurology 2003;61:1789-91.

39. Kossoff EH, McGrogan JR, Bluml RM, Pillas DJ, Rubenstein JE, Vining EP. A modified Atkins diet is effective for the treatment of intractable pediatric epilepsy. Epilepsia 2006;47:421-4.

40. Kossoff EH, Rowley H, Sinha SR, Vining EP. A prospective study of the modified Atkins diet for intractable epilepsy in adults. Epilepsia 2008;49:316-9.

41. Kossoff EH, Dorward JL, Turner Z, Pyzik PL. Prospective study of the Modified Atkins Diet in combination with a ketogenic liquid supplement during the initial month. J Child Neurol 2011;26:147-51.

42. Kossoff EH, Dorward JL, Miranda MJ, Wiemer-Kruel A, Kang HC, Kim HD. Will seizure control improve by switching from the
Modified Atkins Diet to the traditional Ketogenic Diet? Epilepsia 2010;51:2496-9.

43. Nizamuddin J, Turner Z, Rubenstein JE, Pyzik PL, Kossoff EH Management and risk factors for dyslipidemia with the ketogenic diet. J Child Neurol 2008;23:758-71.

44. Bergqvist AG, Schall JI, Stallings VA. Vitamin D status in children with intractable epilepsy, and impact of the ketogenic diet. Epilepsia 2007;48:66-71.

45. McNally MA, Pyzik PL, Rubenstein JE, Hamdy RF, Kossoff EH. Empiric use of oral potassium citrate reduces symptomatic kidney stone incidence with the ketogenic diet. Pediatrics 2009;124:e300-4.

46. Groesbeck DK, Bluml RM, Kossoff EH. Long-term use of the ketogenic diet in the treatment of epilepsy. Dev Med Child Neurol 2006;48:978-81.

47. Barborka CJ. Epilepsy in adults: Results of treatment by ketogenic diet in one hundred cases. Arch Neurol 1930;6:904-14.

48. Barañano KW, Hartman AL. The ketogenic diet: Uses in epilepsy and other neurologic illnesses. Curr Treat Options Neurol 2008;10:410-9.

49. Seyfried TN, Kiebish M, Mukherjee P, Marsh J. Targeting energy metabolism in brain cancer with calorically restricted ketogenic diets. Epilepsia 2008;49 Suppl 8:114-6.

50. Schmidt M, Pfetzer N, Schwab M, Strauss I, Kämmerer U. Effects of a ketogenic diet on the quality of life in 16 patients with advanced cancer: A pilot trial. Nutr Metab 2011;8:54.

51. Van der Auwera I, Wera S, Van Leuven F, Henderson ST. A ketogenic diet reduces amyloid beta 40 and 42 in a mouse model of Alzheimer's disease. Nutr Metab (Lond) 2005;2:28

52. Henderson ST. Ketone bodies as a therapeutic for Alzheimer's disease. Neurotherapeutics 2008;5:470-80.

53. Kossoff EH, Huffman J, Turner Z, Gladstein J. Use of the modified Atkins diet for adolescents with chronic daily headache. Cephalalgia 2010;30:1014-6.

54. Maggioni F, Margoni M, Zanchin G. Ketogenic diet in migraine treatment: A brief but ancient history. Cephalalgia 2011;31:1150-1.

55. Kossoff EH, Hartman AL. Ketogenic Diets: New Advances for Metabolism-Based Therapies. Current Opinion Neurol 2012;25:173-8.

56. Nathan JK, Purandare AS, Parekh ZB, Manohar HV. Ketogenic diet in Indian children with uncontrolled epilepsy. Indian Pediatr 2009;46:669-73.

57. Ito S, Oguni H. Ketogenic diet for intractable childhood epilepsy; as an early option as well as a last resort. Brain Nerve 2011;63:393-400.

58. Ito Y, Oguni H, Ito S, Oguni M, Osawa M. A modified Atkins diet is promising as a treatment for glucose transporter type 1 deficiency syndrome. Dev Med Child Neurol 2011;53:658-63.

59. Kossoff EH, Dorward JL, Molinero MR, Holden KR. The Modified Atkins Diet: A potential treatment for developing countries. Epilepsia 2008;49:1646-7. 